\title{
LONG-TERM URETHRAL CATHETERISATION AFTER SPINAL INJURY
}

\author{
By J. B. Cook, M.D., M.R.C.P. and P. H. SMITH, M.B., F.R.C.S. \\ Spinal Injuries Unit, Pinderfields General Hospital, Wakefield
}

THE management of patients who are incontinent of urine is always difficult and is to some extent dependent upon the cause of the incontinence and upon the age and general condition of the patient. Whilst reassurance and simple drug therapy may be adequate for the enuretic and a single operation may cure the woman with stress incontinence and the man with chronic retention, the problem is more complex in patients with neurological disorders of bladder function. Though incontinence of urine is their commonest urological complaint, it is important to remember that these patients may have associated renal damage and that the preservation of renal function is more important than the treatment of the incontinence which can always be managed by a urinal in the male and by some form of padding in the female. Investigation may yield evidence of high residual urine, recurrent urinary infections, vesicoureteric reflux (fig. I), hydronephrosis (fig. 2), stone formation (fig. 3) and chronic renal failure.

Functioning renal tissue is best preserved by the control of urinary infections and by the establishment of free drainage of the urinary tract. Infection can usually be controlled by antibiotic therapy, by abolishing residual urine and by removing urinary calculi, but the establishment of free drainage of the urinary tract is rather more difficult and may involve the use of bladder training, carbachol and surgical procedures including transurethral resection of the bladder neck and external sphincter. It has also been suggested that there may be a place for division of the pudendal or sacral nerves (Ross, I956; Misak, et al., I962).

Such procedures are adequate for the majority of patients, but a few fail to void satisfactorily, develop hydronephrosis, vesicoureteric reflux or suffer recurrent attacks of pyelonephritis. These patients require further treatment to guarantee free urinary drainage. This may be by means of an indwelling urethral catheter; by suprapubic cystotomy, anterior transposition of the urethra (Griffiths, I960), or cutaneous vesicostomy (Lapides, Ajemian and Lichtwardt, I960); or by urinary diversion, using an ileal or colonic conduit (Pyrah, I957; Mogg, 1965), or by cutaneous ureterostomy (Lapides, 1962). Unfortunately each method has its drawbacks. The urethral catheter causes a urethritis which may be followed by a urethral stricture or fistula and bladder stones tend to form around the balloon as it lies in the bladder. Suprapubic cystotomy does not provide dependant drainage, anterior transposition of the urethra has a limited application and cutaneous vesicostomy is not generally successful (Krahn, Morales and Hotchkiss, I964). Urinary diversion, though frequently advised in the past, is not without mortality and morbidity (Creevy, I960; Bowles, Cordonnier and Parsons, I964), and is probably best avoided except in the patients with progressive deterioration of renal function associated with obstruction and persistent infection (Ross, r967).

An appreciation of these facts led us to believe that a urethral catheter might be not only the simplest but also the best alternative in these patients and this paper records the results of a controlled study of nine paraplegic and eleven tetraplegic 


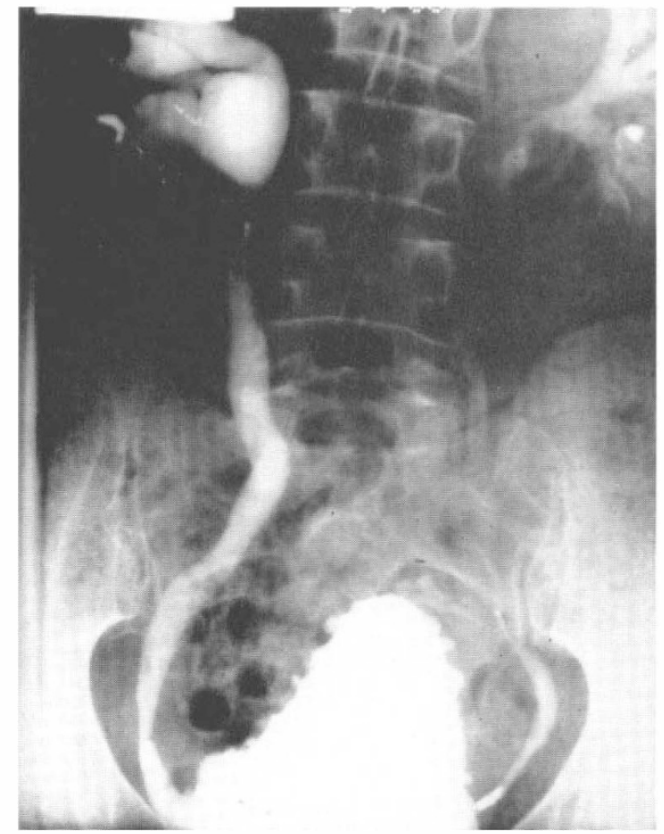

FIG. I

Bilateral vesicoureteral reflux associated with a neurogenic bladder.

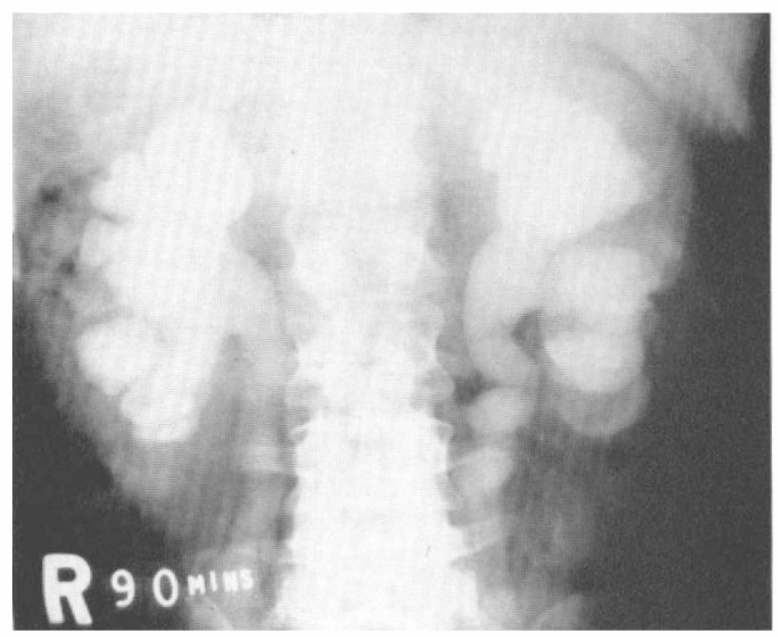

FIG. 2

Bilateral hydronephrosis 16 years after a lower dorsal paraplegia due to an epidural abscess. 
patients treated at the Spinal Injuries Unit at Pinderfields General Hospital, Wakefield, who have used an indwelling urethral catheter from two to nine years (fig. 4).

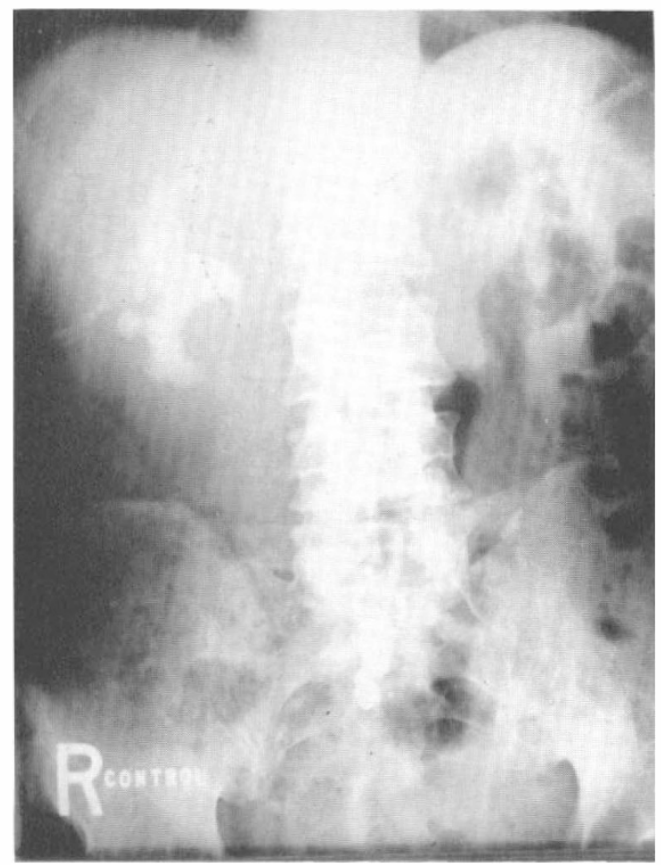

FIG. 3

Bilateral staghorn calculi 5 years after spinal cord damage.

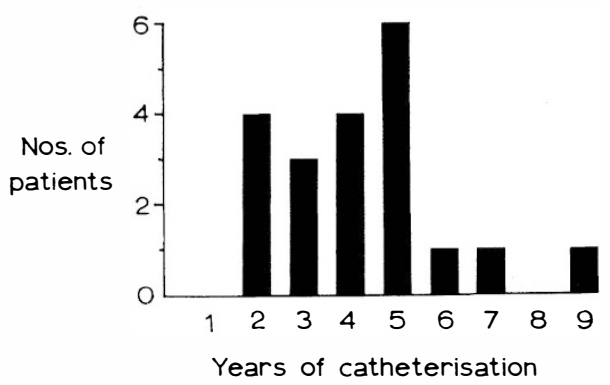

FIG. 4

Duration of catheterisation of the patients studied.

This is a small unit of 26 beds which opened in 1954 and which has admitted 330 new cases since the beginning of 1958, during which time 20 patients have been treated by long-term urethral catheterisation, an incidence of approximately six per cent. 


\section{METHOD}

The catheterised patients have been compared with a control series of paraplegics and tetraplegics whose lesions are of similar level and duration and who, except for the first few weeks after injury, have managed without catheters. It has not, however, been possible to match the groups by sex and age and as a result there are nine females in the catheterised group and four in the control group. The average ages of the control and catheterised groups are 34 and 33 years, but the difference in age in any one pair varies from $\mathrm{I}$ to 29 years.

Each patient has used a latex Foley catheter which has been changed every 7 to 14 days at the hospital, at home by the district nurse or, after suitable training, by the relatives.

All patients have been seen and questioned about any difficulties with their catheters, the incidence of urinary infections and the presence of stones. They have also been examined to detect any urethral pathology and investigated for evidence of urinary infection, stone formation and renal failure. Each patient had several mid-stream or cather specimens of urine, samples of blood were taken for estimation of blood urea, serum electrolytes and serum calcium, and intravenous pyelograms were carried out.

\section{RESULTS}

Table I shows the results of these urological investigations and it will be noted that there is a similar incidence of clinical and bacteriological urinary infection and

\section{TABLE I}

Results of Urological Investigation in Patients With and Without Indwelling Urethral Catheters

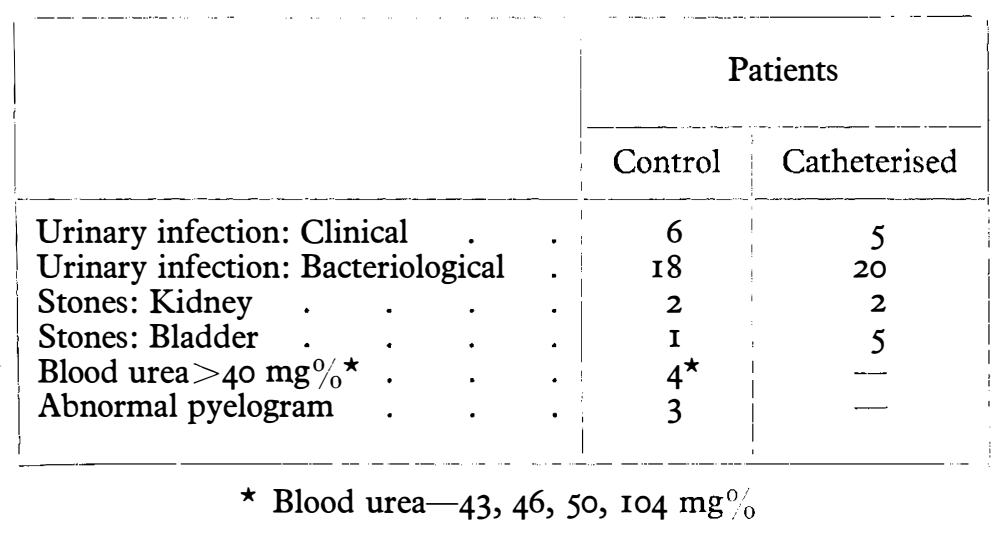

of renal stone formation in the two groups. However, the catheterised patients have more normal pyelograms and better renal function despite a higher incidence of bladder stone formation.

Episodes of Clinical Urinary Infection. Five of the six affected patients in the control group had suffered multiple attacks of pyelonephritis whilst the sixth 
had occasional 'cystitis' only. The catheterised patients differed in that two had multiple and two solitary attacks of pyelonephritis, whilst the fifth had one episode of epididymo-orchitis.

Persistent Infection of the Urine. Repeated bacteriological examination showed a chronic bacilluria in 18 of the 20 control patients and in all those catheterised. The findings in the catheterised patients were to be expected (Talbot, Mahoney and Jaffee, I959), but the incidence in the control group seems unduly high.

Renal Stones. Two of the catheterised patients formed renal stones. One had a staghorn in the upper half of one kidney, whilst the other formed several small stones in one kidney in the first year after injury, all of which have now been passed spontaneously. Both the control patients with renal stones had symptomless staghorn calculi. None of these patients showed evidence of hyperparathyroidism.

Bladder Stones. The preponderance of bladder stones in the catheterised group was expected but it is interesting to note that only two of the five catheterised patients who developed bladder stones suffered from clinical urinary infection.

Sixteen catheterised patients suffered catheter blockage occasionally and whilst this was inconvenient to all, it was troublesome only to the tetraplegics who developed headache, sweated and became flushed, hypertensive and increasingly spastic.

Blood Urea and Intravenous Pyrelogram. All the catheterised patients had normal renal function as shown by blood urea. However, four of the control patients had a raised blood urea and the pyelographic findings in these patients are recorded in Table II.

TABLE II

Pyelographic Findings in Control Patients with Raised Blood Urea

\begin{tabular}{|c|c|}
\hline Blood urea $\mathrm{mg} \%$ & Intravenous pyelogram findings \\
\hline $\begin{array}{l}43 \\
46\end{array}$ & $\begin{array}{l}\text { Normal } \\
\text { Bilateral staghorn calculi }\end{array}$ \\
\hline 50 & Bilateral hydronephrosis + hydroureter \\
\hline IO4 & Bilateral hydronephrosis + hydroureter \\
\hline
\end{tabular}

Both patients with hydronephrosis had vesicoureteric reflux. One of these has now been catheterised with improvement and the other has been treated elsewhere by urinary diversion.

Urethral Complications. No patient has developed a periurethral abscess, urethral fistula or urethral stricture. 


\section{DISCUSSION}

Bladder training is the mainstay of the management of the bladder in multiple sclerosis and spinal injury whilst drugs which stimulate or depress the detrusor muscle may be used to assist such training. In addition, operations upon the bladder neck, the external sphincter and the pudendal and sacral nerves may also be required in order to reduce urethral resistance.

Most patients can be satisfactorily managed by one or other of these techniques, but a few fail to void satisfactorily, some develop vesicoureteric reflux with hydronephrosis and others suffer recurrent attacks of pyelonephritis with progressive renal destruction. Such patients inevitably develop chronic renal failure unless they are provided with free drainage of urine by some form of diversion or by urethral catheterisation. Comarr (196I) and Gibbon (1966) are both of the opinion that prolonged catheter drainage is preferable to poor bladder function and we should like to endorse these views. It is also much simpler to pass a urethral catheter than it is to divert the urine in these disabled patients and we would suggest that urinary diversion be reserved for the very few patients whose obstructive signs do not improve after catheterisation or who cannot or will not tolerate a urethral catheter.

\section{SUMMARY}

A controlled study of the effect of long-term urethral catheterisation upon renal function has been undertaken in 40 paraplegic patients. All the catheterised patients had a normal blood urea and intravenous pyelogram whilst four of the control group showed evidence of impaired renal function. The catheterised patients were more likely than the controls to develop bladder stones, but these are easily crushed and removed and we believe that the hazards of the urethral catheter are less than those of imperfect bladder function and of operations for diversion of the urine.

\section{ACKNOWLEDGMENT}

We should like to acknowledge the support of the Multiple Sclerosis Society throughout this study.

\section{REFERENCES}

Bowles, W. T., Cordonnier, J. J. \& Parsons, R. P. (I964). F. Urol. 92, 627.

Comarr, A. E. (1961). 7. Urol. 85, 983.

CREEVY, C. D. (1960). F. Urol. 83, 394 .

GibBon, N. O. K. (I966). Acta neurol. scand. Suppl. 20, 42, I 33.

GRIFFITHS, I. H. (I960). Br. F. Urol. 32, 27.

Krahn, H., Morales, P. \& Hotchkiss, R. (I964). F. Urol. 91, 246.

LAPIDES, J., AJEMIAN, E. P. \& LiCHTWARDT, J. R. (I960). F. Urol. 84, 609.

LAPIDES, J. (1962). F. Urol. 88, 735.

Misak, S. J., BunTs, R. C., UlmeR, J. L. \& Eagles, W. M. (1962). F. Urol. 88, 392.

MOGG, R. A. (1965). Br. F. Urol. 37, 681.

PyRAh, L. N. (1957). F. Urol. 78, 683.

Ross, J. C. (1956). Br. F. Urol. 28, I4.

Ross, J. C. (1967). Paraplegia 4, 209.

Talbot, H. S., Mahoney, E. M. \& Jaffee, S. R. (I959). F. Urol. 8i, iz8. 